Editorial

\title{
Grow Up, Level Up, and Game On; Evolving Games Research
}

\author{
Julia Kneer ${ }^{1, *}$ and Ruud S. Jacobs ${ }^{2}$ \\ ${ }^{1}$ Department of Media and Communication, Erasmus University Rotterdam, 3062PA Rotterdam, The Netherlands; \\ E-Mail: kneer@eshcc.eur.nl \\ 2 Department of Communication Science, University of Twente, 7522NB Enschede, The Netherlands; \\ E-Mail: r.s.jacobs@utwente.nl \\ * Corresponding author
}

Submitted: 7 May 2018 | Published: 7 June 2018

\begin{abstract}
Playing host to articles written in different disciplines and perspectives on the shared subject of digital gaming, the current thematic issue means to galvanise interest in and recognition of the nascent field of games research. Despite being little more than 50 years old, the medium of digital games has seen a meteoric rise to economic and cultural prominence across the globe. A cultural shift accepting games as a worthwhile recreational activity (and more) is likewise resulting in shifting attentions within game studies. Games were seen as frivolous and even harmful, and research traditionally focused on the negative effects they were perceived to have while in the end coming up with very little reliable evidence to support this position. The current wave of games research exemplified in this issue is certainly wider: games are a cultural and often highly socialised medium that has changed the way we view the world. They are used in non-entertainment settings, helping to promote active learning in players of all ages. The medium also facilitates deeper psychological and philosophical theorizing, as researchers grapple with deeper questions on what games and play mean to each of us. Put simply: games research is not just fun and games.
\end{abstract}

\section{Keywords}

culture; digital games; effects; serious games; social panic

\section{Issue}

This editorial is part of the issue "Games Matter? Current Theories and Studies on Digital Games", edited by Julia Kneer (Erasmus University Rotterdam, The Netherlands) and Ruud Jacobs (University of Twente, The Netherlands).

(C) 2018 by the authors; licensee Cogitatio (Lisbon, Portugal). This article is licensed under a Creative Commons Attribution 4.0 International License (CC BY).

\section{Introduction}

This thematic issue gives an overview of the huge diversity of game studies in current research on games. Game studies might still be considered a relatively new scientific field, including perspectives from psychology, communication research, media science, philosophy, art, design, computer science and more. However, digital games themselves are not that new, dating back to 1962 with Spacewars! being developed at MIT. In the early 1970s Pong (Atari, 1972), the first commercially available computer game, was designed and placed in public locations. With the launch of the Atari VCS video game console in 1977, game computers soon started coming into the homes of a new but quickly growing audience of players.
This growth has not yet stopped. The report of the Entertainment Software Association states that nowadays $67 \%$ of all US households own at least one device that is used to play digital games (Entertainment Software Association, 2017). In addition, digital games cannot be considered to be a leisure activity for young men only; the average player is actually 37 years old and women play as much as men do. Despite the rising numbers of players, games are still often perceived as a dangerous and negative new technological development by policy makers and non-gaming audiences. Research has picked up on this debate, resulting in an avalanche of studies revolving around possible detrimental effects (e.g., Elson \& Ferguson, 2013; Ferguson, 2008; Ivory et al., 2015). Studies on a more general level consider this debate and the 
ambivalent research results found as a generational conflict between younger and older societal groups (Ivory \& Kalyanaraman, 2009; Kneer, Glock, Beskes, \& Bente, 2012; Kneer, Munko, Glock, \& Bente, 2012; Quandt, Chen, Mäyrä, \& van Looy, 2014), both inside and outside of academia. These studies have one thing more or less in common: negative attitudes disappear with own playing experience and/or being part of the playing generation. Thus, some scientists are even expecting prejudice against games and players to be gone within the next generation, as there will hardly be anyone left who does not have first-hand playing experience. The results of the meta-analyses mentioned above showed that games simply cannot be said to unequivocally cause negative behavioural outcomes. Indeed, the demand to stop presenting digital games as cause for school shootings and other terrible events was supported by the US Supreme Court, which ruled in 2011 that there was no connection between violent games and real life aggression.

After all, no one plays games in order to become aggressive or addicted, or to develop any other negative tendencies. Thus, the academic discussion concerning games moved beyond the mere focus on negative effects games might or might not have and targets more and more the importance of digital games as part of daily life, including positive effects (e.g., Ferguson, 2007; Reinecke, Klatt, \& Krämer, 2011; Rieger, Frischlich, Wulf, Bente, \& Kneer, 2014), motivations for game play (e.g., Przybylski, Weinstein, Murayama, Lynch, \& Ryan, 2012; Tamborini, Bowman, Eden, Grizzard, \& Organ, 2010), and persuasive effects (Jacobs, 2016), among others.

Nevertheless, researchers that are studying a medium that is just over half a century old and still developing at an accelerating pace are not always taken that seriously. Some who see digital games as a purely youth-oriented leisure activity might question if games research is even necessary at all. Who is a player after all?

In fact, looking at the constantly rising numbers coming from the game industry (Entertainment Software Association, 2017), it can be concluded that digital games have become an indispensable part of human life-for younger and older generations. The stereotype about game researchers doing this research because they are players themselves will start to fade, and the question 'who is a player after all?' will be replaced by the question 'who is not a player after all?'.

The contributions to this thematic issue grapple with the maturation of games in society in three ways. First, the contributions take a broad cultural perspective, discussing games as fondly remembered pastimes, social glue, and artistic expression. Second, we take a closer look at serious games, those games that have been designed to offer experiences beyond entertainment. The last two contributions open up the fabric of games, discussing how they make us think (about them) and how we as researchers should view them.

Many young and middle aged adults remember playing digital games such as Pong, Pacman, Mario Kart
(Atari, 1972, Namco, 1980, and Nintendo, 1992, respectively) and others in their youth, creating feelings of nostalgia. As these adults attribute meaning to their time spent gaming all those years ago, the first article of this thematic issue from Wulf, Bowman, Rieger, Velez and Breuer (2018) explains how digital games are able to induce nostalgic feelings and how these feelings are related to well-being of players.

If digital games are able to create feelings of nostalgia, we have to consider them as a cultural part of our lives. Do you maybe remember going to Arcade Game halls yourself or meeting up with friends for all-night LAN parties? If so, you already know that games can create social events (Jansz \& Martens, 2005). Thus, the stereotype of the lonely male child that sits in the basement and plays digital games alone disappears slowly, and is replaced by the idea of games as cultural good. In the second article of this issue, Love (2018) explores social game events and how participating is necessary to understand games as culture not only for researchers but for game designers as well. That game cultures might even have the power to shift national and global boundaries is analysed by Elmezeny and Wimmer (2018). The third piece on games as culture from Szabo (2018) presents Psychasthenia Studio, an interdisciplinary art collective, as another paradigm. Their working process demonstrates how digital games go beyond straightforward entertainment or communication and can be a medium of (artistic) expression.

Despite the idea of games as cultural good, one might argue that digital games are nothing new. They would say digital games are just games packaged in a new technological form. The idea of (any) games being important for human well-being and society is indeed well-known since the beginning of mankind. Some might even state that digital games are just a (new) form of distraction from real life and from societal problems, pointing back to the idea of 'panem et circenses' (bread and games) in Ancient Rome. However, games are nowadays not only used for entertainment and distraction but also offer deeper socio-political meaning. Two papers coming from the research topic of Serious Games are targeting exactly this idea: if and how games can be used for persuasion and learning (Jacobs, Jansz, \& de la Hera Conde-Pumpido, 2017). While de la Hera Conde-Pumpido (2018) explores the impact of cancer games and shows the positive output beyond persuasion, Hébert, Jenson and Fong (2018) give insight in the complexity of measuring learning effects of games via one case study.

In the final parts of this issue we turn our perspective inward. By their design, games consist of rules, systems, and interactions. Those interactions are made possible by the way we as players think how the game works. The seventh article in this thematic issue by McGloin, Wasserman and Boyan (2018) discusses these thoughts as mental models. After describing how the more fundamental conception of mental models works with the technical, mediated, and procedural aspects of games, 
they show how this way of thinking can transform effects research on this medium. In addition, Willumsen (2018) gives an insight how formalism and formal analyses can be used to study games coming from a philosophical point of view.

Hence, this thematic issue is organized according to these perspectives:

\section{A. Do You Remember?}

"Video Games as Time Machines: Video Game Nostalgia and the Success of Retro Gaming" (Wulf et al., 2018).

\section{B. Games as Cultural Good}

"Do We Need Permission to Play in Public? The Design of Participation for Social Play Video Games at Play Parties and 'Alternative' Games Festivals" (Love, 2018);

"Games without Frontiers: A Framework for Analysing Digital Game Cultures Comparatively" (Elmezeny \& Wimmer, 2018);

"Psychasthenia Studio and the Gamification of Contemporary Culture" (Szabo, 2018).

\section{Serious Games}

"The Persuasive Roles of Digital Games: The Case of Cancer Games" (de la Hera Conde-Pumpido, 2018);

"Challenges with Measuring Learning through Digital Game Play in K-12 Classrooms" (Hébert et al., 2018).

\section{Behind Games Research: Theory and Method}

"Model Matching Theory: A Framework for Examining the Alignment between Game Mechanics and Mental Models" (McGloin et al., 2018);

"The Form of Game Formalism" (Willumsen, 2018).

This thematic issue hopes to give a blanket answer to the perennial question game researchers are asked: 'So you play games all day?' We hope that we could provide an insight into what is really going on behind the curtains of game research and that our thematic issue can show you that games do matter after all. It is important to have an idea how games are researched, how games contribute to well-being and research itself, and which research methods are adequate in the study of games. Now that it is clear that moral panic will not help to understand the phenomenon of digital games, it is time to accept games as an integral part of modern life. To sum up, game on!

\section{Acknowledgments}

This work is part of the research programme 'Persuasive Gaming. From theory-based design to validation and back' with project number 314-99-106 which is (partly) financed by the Netherlands Organisation for Scientific Research (NWO).

\section{Conflict of Interests}

The authors declare no conflict of interests.

\section{References}

De la Hera Conde-Pumpido, T. (2018). The persuasive roles of digital games: The case of cancer games. Media and Communication, 6(2), 103-111.

Elmezeny, A., \& Wimmer, J. (2018). Games without frontiers: A framework for analyzing digital game cultures comparatively. Media and Communication, 6(2), 80-89.

Elson, M., \& Ferguson, C. (2013). Twenty-five years of research on violence in digital games and aggression: Empirical evidence, perspectives, and a debate gone astray. European Psychologist, 19, 33-46. doi:10.1027/1016-9040/a000147

Entertainment Software Association. (2017). Essential facts about the video and computer game industry. Retrieved from http://www.theesa.com/wpcontent/uploads/2017/04/EF2017_FinalDigital.pdf

Ferguson, C. (2007). The good, the bad and the ugly: A meta-analytic review of positive and negative effects of violent video games. The Psychiatric Quarterly, 78(4), 309-316. doi:10.1007/s11126-007-9056-9

Ferguson, C. (2008). The school shooting/violent video game link: Causal link or moral panic? Journal of Investigative Psychology and Offender Profiling, 5, 25-37. doi:10.1002/jip.76

Hébert, C., Jenson, J., \& Fong, K. (2018). Challenges with measuring learning through digital game play in k-12 classrooms. Media and Communication, 6(2), 112-125.

Ivory, J. D., \& Kalyanaraman, S. (2009). Video games make people violent-Well, maybe not that game: Effects of content and person abstraction on perceptions of violent video games' effects and support of censorship. Communication Reports, 22(1), 1-12. doi:10.1080/08934210902798536

Ivory, J. D., Markey, P. M., Elson, M., Colwell, J., Ferguson, C., Griffiths, M. D., . . Williams, K. D. (2015). Manufacturing consensus in a diverse field of scholarly opinions: A comment on Bushman, Gollwitzer, and Cruz (2015). Psychology of Popular Media Culture, 4(3), 222-229. doi:10.1037/ppm0000056

Jacobs, R. (2016). Play to win over: Effects of persua- 
sive games. Psychology of Popular Media Culture. doi:10.1037/ppm0000124

Jacobs, R., Jansz, J., \& de la Hera Conde-Pumpido, T. (2017). The key features of persuasive games: A model and case analysis. In R. Kowert \& T. Quandt (Eds.), New perspectives on the social aspects of digital gaming: Multiplayer 2 (pp. 153-171). New York: Routledge.

Jansz, J., \& Martens, L. (2005). Gaming at a LAN event: The social context of playing video games. New Media and Society. 10.1177/1461444805052280

Kneer, J., Glock, S., Beskes, S., \& Bente, G. (2012). Are digital games perceived as fun or danger? Supporting and suppressing different game-related concepts. Cyberpsychology, Behavior, and Social Networking, 15(11), 604-609. doi:10.1089/cyber.2012.0171

Kneer, J., Munko, D., Glock, S., \& Bente, G. (2012). Defending the doomed: Implicit strategies concerning protection of First-Person Shooter games. Cyberpsychology, Behavior and Social Networking, 15(5), 251-256. doi:10.1089/cyber.2011.0583

Love, L. H. C. (2018). Do we need permission to play in public? The design of participation for social play video games at play parties and 'alternative' games festivals. Media and Communication, 6(2), 69-79.

McGloin, R., Wasserman, J. A., \& Boyan, A. (2018). Model matching theory: A framework for examining the alignment between game mechanics and mental models. Media and Communication, 6(2), 126-136.

Przybylski, A. K., Weinstein, N., Murayama, K., Lynch, M. F., \& Ryan, R. M. (2012). The ideal self at play: The appeal of video games that let you be all you can be. Psychological Science, 23(1), 69-76. doi:10.1177/ 0956797611418676

Quandt, T., Chen, J., Mäyrä, F., \& van Looy, J. (2014). Gaming around the globe? A comparison of gamer surveys in four countries. In T. Quandt \& S. Kröger (Eds.), Multiplayer. The social aspects of digital gaming (pp. 23-46). London: Routledge.

Reinecke, L., Klatt, J., \& Krämer, N. C. (2011). Entertaining media use and the satisfaction of recovery needs: Recovery outcomes associated with the use of interactive and noninteractive entertaining media. Media Psychology, 14(2), 192-215. doi:10.1080/ 15213269.2011.573466

Rieger, D., Frischlich, L., Wulf, T., Bente, G., \& Kneer, J. (2014). Eating ghosts: The underlying mechanisms of mood repair via interactive and noninteractive media. Psychology of Popular Media Culture, 4(2), 138-154. doi:10.1037/ppm0000018

Szabo, V. (2018). Psychasthenia studio and the gamification of contemporary culture. Media and Communication, 6(2), 90-102.

Tamborini, R., Bowman, N. D., Eden, A., Grizzard, M., \& Organ, A. (2010). Defining media enjoyment as the satisfaction of intrinsic needs. Journal of Communication, 60(4), 758-777. doi:10.1111/j.14602466.2010.01513.x

Willumsen, E. C. (2018). The form of game formalism. Media and Communication, 6(2), 137-144.

Wulf, T., Bowman, N. D., Rieger, D., Velez, J. A., \& Breuer, J. (2018). Running head: Video game nostalgia and retro gaming. Media and Communication, 6(2), 60-68.

\section{About the Authors}

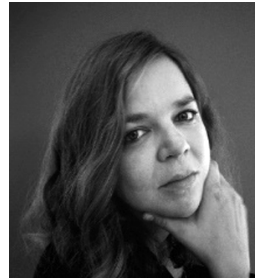

Dr. Julia Kneer is an Assistant Professor in the Department of Media and Communication at Erasmus University Rotterdam. Her research focus lies on digital games, especially how digital games and players are perceived, generational differences, and digital game addiction. She is a member of the editorial board of the Journal of Media Psychology and the current chair of the Games Studies Division of the International Communication Association.

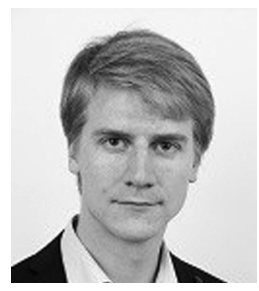

Dr. Ruud Jacobs is an Assistant Professor in the Department of Communication Science at the University of Twente. In 2017, he defended his dissertation on the persuasive effects of serious games that he wrote as part of the nationally-funded interdisciplinary Persuasive Gaming in Context project. His research focus lies on the psychological elements of meaning in media that are typically perceived as entertainment. 